\title{
VAGUS AND GLOSSOPHARYNGEAL NERVE PARALYSIS: CASE REPORT ${ }^{1}$
}

\author{
M. KeÉRI-SZÁNTó, M D., and M. BELZILE, M D , M S. (N.Y.U.)
}

Disturbances of cranial nerves following general anaesthesia are rare and, of all the cranial nerves, the vagus is least frequently involved (5). The fo lowing case appears, therefore, to be worth reporting since it concerns extensive bilateral involvement of the ninth and tenth nerves in all their aspects, sensory, motor, and autonomic

\section{Case Report}

A 35-year-old well-nourished male entered the neurosurgical service of the hospital with a five-year history of headache Several years before he had a questionable cerebrovascular accident which cleared up completely Anjrographic study, carned out uneventfully under general anaesthesia, revealed a "le_t frontal space-occupying lesion." History and laboratory finding, were otherwise non-contributory

Craniotomy was scheduled or the day following an jlography. Anaesthetic induction and intubation were uneventful with thropental anc suxamethonium, producing no change in systolic blood pressure $(150 \mathrm{~mm} \mathrm{Hg})$ and Julse rate $(100 / \mathrm{min}$.). Respirations were manually controlled Twenty-five minutes a-ter the start of anaesthesia, the Jatient was turned on his side for placement of a spinal needle. During this manipu-ation he coughed lightly twice Anaesthesia was immediately deejened with more thiopental It was noted that the systolic blood pressure rose to 170 w.ule the julse rate dropped to 70. Installation was completed $50 \mathrm{~mm}$. after starting the anaest.esia and preparation of the surgical field was started About $60 \mathrm{cc}$. of a 04 per cent dibucame solution with 3 drops of adrenalin 11,000 to $100 \mathrm{cc}$. were imjected into the scalp. Simultaneously, the patient was connected to a mechanical respirator and was given $100 \mathrm{mg}$ gallamine tri-1odide intravenously Vital signs were cgain checked as soon as installation was completed and the patient's condition was found to be radically changed The blood pressure rose and soon reached $240 \mathrm{~mm} \mathrm{Hg}$ and the pulse rate mounted from $65-70$ to $180 / \mathrm{mm}$ in less than $10 \mathrm{~min}$ The surgeons were alerted and surgery stopped as the skin flap was rased. Twenty minutes after the onset of the hypertensive ejisode, his blood pressure started to drop sharply with the pulse rate remaining at $-70 / \mathrm{min}$. Vasopressors and whole blood under positive pressure were administered as the systolic pressure dropped below $100 \mathrm{~mm} \mathrm{Hg}$ and the patient was given 100 per cent oxygen via the respirator His colour remamed excellent and his skın warm and dry, but, in spite of all efforts, his pulse disappeared 30 min. after the onset of defficulties Some trme was lost convincing ourselves that cardiac arrest had occurred because his collour was stall excellent When finally a skin incision was made over the thorax, bleeding was noted from the wound and a few seconds later the pulse returned, making it unnecessary to open the chest The pressure soon stabllized around $80 \mathrm{~mm} \mathrm{Hg}$ and the pulse rate at $120 / \mathrm{min}$. The chest incision was closed and

1The authors are indebted to Dr C Bertrand, FRCS (.C) for referral of his patient and for his interest and helpful criticism in the preparation of this manuscript

A preliminary report of the anaesthetic aspects of this case was published anonymously in the A S A monthly Newsletter (No. 200), the comments of several anaesthesiologists, appearing subsequently in the same journal, are gratefully acknowledged

'From the Anaesthesia and ENT Services of Notre Dame Hospital, Montreal 
the patient was observed for a time. Since there was a possibility that the bram had hemiated, it was finally decided to carry on The brain was first visualized about $1 \mathrm{hr}$. after the curculatory arrest and showed none of the usual signs of herniation, though ventricular pressure was higher than normal In the course of a $5 \frac{1}{y^{\prime}}$-hour operation, a cystic meningoblastoma was removed from the left fronto-panetal region The anaesthetic course was without further incidents The patient was extubated $10 \mathrm{~mm}$ after the end of surgery. at that time he obeyed spoken commands and answered questions. On the evening of the same day he recognized people whom he had only met just before surgery $\mathrm{He}$ was quite hoarse The following day his voice became worse and he was somewhat confused Then, $48 \mathrm{hrs}$ after surgery, it was first noticed that the patient was unable to swallow and aspirated everything he took by mouth Laryngological examination revealed bilateral motor paralysis of the ninth and tenth nerves, comslete anaesthesia of the root of the tongue and the larynx, with diminished sensation o_ the bronchial mucosa Additional findir.gs were a right Horner's syndrome, "jelly"-nystagmus and left hemianopia, left facial nerve paresis, and persistent tachycardıa, between 120 and $140 / \mathrm{mm}$ Diarrhoea was not noted at any time In view of the fact that bronchial aspiration was easily performed in this patient, he was put on tube feeding and tracheotomy was delayed until almost three weeks after surgery when there appeared no trace of recovery of the laryngeal reflexes His general course was otherwise quite satısfactory and he was discharged from the hospi al four weeks after surgery. At the tume he was still unable to swallow, had to se tube-fed, and his pulse remained around $100 / \mathrm{mm}$ at rest

The patient started to regain control of his pharynx and larynx about two weeks after his discharge At present (12 months after surgery), his tracheotomy is closed, his laryngeal sensations have returned, and he swallows well With a still paralyzed left vocal cord and left pharyngeal musculature, he has made a full functional recovery He has shght rotatory nystagmus and almost complete left hemianopia which have been stationary for the past six months His pulse is now in the high normal range and his exercise tolerance is excellent $\mathrm{He}$ has returned to his previous job in a brokerage firm

\section{Comment}

The case history suggests a brain-stem lesion involving mostly the nuclei of the ninth and tenth nerves The lesion was mitially bilateral and receded in the course of a few months untll it now appears permanent and sharply localized

In animal experıments high section of both vagi causes pulmonary oedema and is rapidly fatal The resistance of such anumals against adrenalin is sharply reduced $(9)$.

In humans $(1,2,3,4)$ the transected vagus nerves were usually diseased and in only one instance $(2,4)$ were both vag1 cut Tachycardia is a constant feature in these reports, subsiding some time after surgery except where both nerves are cut. Hypertension has not been noted For the sake of completeness, one should also mention that there is good experimental evidence for sensory representation of the larynx in the reticular substance and the cortex $(6,7)$. Some authors also postulate a higher laryngeal centre in the same sense as the oculomotor system $(8,10)$.

Our patient evidently suffered a transient and unusually severe haemodynamic upset following a rather banal mcident during installation. He had a peculiar involvement of the cranial nerves which lasted for several weeks and he now 
apparently has perrnanent residual lesions which can be localized to the left nucleus ambiguus, the oculomotor system, and the left visual cortex. Chances are overwhelmingly against the possibility that these lesions occurred independently of each other The haemianopia is certanly due to anoxia, which in turn was brought on by the tachycardic episode. What explanation can be offered for the latter?

Surgical trauma cannot be considered more than an aggravating factor because the difficulties started before surgery got under way. Thus, the initial insult durng installation was most probably caused by anoxia of a small cluster of cells and hypoxıa of a larger surrounding area. This precarıous equilibrium was prolonged for several days owing to the mevitable cerebral oedema after brain surgery It caused sufficient anatomical damage to require relearning of reflex pathways and compensation for the paralysed muscles by the remaining active elements. This would account for the unusually long interval between injury and recovery Alternatively, the prolonged recovery may be explained by damage to the supranuclear pathways and centres durmg surgery added to the anatomical lesion produced during installation.

On this basis the following might have been the sequence of events At the time of positioning, the rostral portion of the left nucleus ambiguus and the left solitary tract nucleus became etther compressed or otherwise deprived of their blood supply It is impossible to say what rendered this usually wellprotected area vulnerable in our patient. The break in the cardio-regulatory servo-loop, involving these synapses and the left carotid sunus, suddenly abolished the cardio-inhibitor efferent vagal impulses. Simultaneously adrenalin was injected into the thus sensitized (9) patient The resulting tachycardia and hypertension could explain the ensuing circulatory fallure through sheer my̌ocardial exhaustion. During the postoperative stage cerebral oedema increased the size of the brain-stem portion where the blood supply was marginal. This lamellar area now involved the contralateral ninth and tenth nucles as well, while the twelfth nerve nucles (located between the opposite ninth and tenth nucles but in more dorsal plane) remained intact. As the cerebral oedema subsided and the blood supply of the area stabilized, a reintegration of laryngeal and pharyngeal functions began, leading in a few months to full compensation for the permanently paralysed elements.

It is appreciated that it is not conclusively proven that vagal or glossopharyngeal paralysis was complete at any time in our patient. Nevertheless the scarcity of reports about the paralysis of these nerves in humans and the peculiarities of the postoperative course in this subject might justify its recording.

\section{SUMMARY}

Following essentially normal induction and installation for craniotomy, a 35-year-old male developed paroxysmal hypertension and tachycardia which culminated in cardiac standstill. Prompt mitial recovery was followed postoperatively by complete motor and sensory paralysis of the larynx and pharynx as 
well as persistent tachycardia. These symptoms continued for six weeks and the eventual full functional recovery took several months. The accident is tentatively explained, in terms of paralysis of the ninth and tenth nerves and the pertinent literature is reviewed.

\section{REFERENCES}

1 Bruckschwaigen, O Wien med Wchnschr 97111 (1947).

2 Fraser, R, \& Chapman, C New England J. Med. 249837 (1953)

3 Gerbode, F , \& Margulins, G S. J Thoracic Surg. 25429 (1953)

4 Gilbertsen, V A \& Lilleher, C W J Thoracic Surg. 2878 (1954)

5 KeAting, $V$ Anaesthetic Accidents Chicago Year Book Publ Co (1956)

6 LAM, R L., \& OgurA, J H Laryngoscope $62 \cdot 486$ (1952)

7 Lam, R. L, \& Ogura, J H Neurology 4630 (1954)

8 LeMEr, F Am. J Anat 51417 (1932).

9 LrTwin, J Acta physiol. Polon. 7141 (1956)

10 Pressman, J J , \& Kelemen, G Physiol Rev 3.5. 506 (1956) 